\title{
Papanicolaou-Stained Cytosmear Preparations in the Evaluation of Leucocytospermia: A Tertiary Centre Experience and Assessment of Utility
}

\author{
Vandana Puri ${ }^{1}$ Kavita Gaur ${ }^{1}$ Sunaina Hooda ${ }^{1}$ Shailaja Shukla ${ }^{1} \quad$ Sunita Sharma ${ }^{1}$ \\ ${ }^{1}$ Department of Pathology, Lady Hardinge Medical College, \\ Shaheed Bhagat Singh Marg, New Delhi, India \\ Address for correspondence Kavita Gaur, MD, DNB, Department of \\ Pathology, Lady Hardinge Medical College, Shaheed Bhagat Singh \\ Marg, New Delhi 110001, India (e-mail: kavgaur@gmail.com).
}

\begin{abstract}
Keywords

- leucocytospermia

- infertility

- reactive oxygen species

- semen

Objectives Leucocytospermia is a rare cause of infertility with a variable incidence in infertile men. In many andrology laboratories, semen analysis is primarily centered on analyzing basic parameters (sperm count, motility, and viability). We examined the role of cytomorphological analysis on Papanicolaou (PAP)-stained smears in the work up of male infertility, with special reference to leukocytospermia and assessed the morphological features of sperms in these cases.

Materials and Methods All cases signed out as "leukocytospermia" between November 2017 and January 2018 were evaluated. Cases showing pus cells ( $\geq 1 / 5 \mathrm{hpf}$ ) on cytosmear evaluation were also analyzed. Parameters obtained on modified Neubauer's chamber, wet mount preparations, and autoanalyzer SQA-IIC-P (Medical Electronic Systems, Israel) were tabulated. PAP-stained smears were examined to assess morphological defects and other findings, if any.

Results Out of 348 semen samples, 6 (1.72\%) were diagnosed as leukocytospermia, all displaying pus cells on cytomorphological evaluation. Five cases having white blood cells $<1 \times 10^{9} / \mathrm{L}$ were analyzed, which displayed the presence of pus cells ( $\geq 1 / 5 \mathrm{hpf}$ ) on cytosmear preparations (1.43\%). Nine cases (81.8\%) showed reduced motile sperm concentration, functional sperm concentration, and sperm motility index. Morphological evaluation of the PAP-stained smears showed mid-piece defects in $18.1 \%$ cases.

Conclusion Diligent cytomorphological evaluation of semen is essential to diagnose leukocytospermia, assess morphological defects, and serve as a quality control measure.
\end{abstract}

\section{Introduction}

The World Health Organization (WHO) defines leucocytospermia as the presence of peroxidase positive leucocytes in concentrations of or greater than $10^{6} / \mathrm{mL}$ of semen. ${ }^{1}$ Leucocytospermia has been found in both fertile and infertile men with or without evidence of genital tract

published online June 27, 2021
DOI https://doi.org/

$10.1055 / \mathrm{s}-0041-1730846$ ISSN $0974-2727$ infections. Significant leucocytospermia, however, has more often been described in cases with underlying infection. ${ }^{2}$ Earlier studies found leukocytes to have a positive effect on semen quality as these cells were supposed to scavenge damaged sperms. ${ }^{3,4}$ Recent work, however, suggests that an increase in leucocytes may negatively impact semen quality and morphology due to reactive oxygen species

(C) 2021. The Indian Association of Laboratory Physicians.

This is an open access article published by Thieme under the terms of the Creative Commons Attribution-NonDerivative-NonCommercial-License, permitting copying and reproduction so long as the original work is given appropriate credit. Contents may not be used for commercial purposes, or adapted, remixed, transformed or built upon. (https://creativecommons.org/licenses/by-nc-nd/4.0/).

Thieme Medical and Scientific Publishers Pvt. Ltd. A-12, 2nd Floor, Sector 2, Noida-201301 UP, India 
(ROS)-mediated damage and possibly defective spermiogenesis. ${ }^{5-8}$ Leucocytospermia is a rare cause of infertility with a variable incidence of 2 to $35 \%$ in such cases. ${ }^{9}$ As abnormal sperm morphology and leucocytospermia can affect the outcome of various interventional procedures involved in infertility management, reporting of leucocytospermia and associated morphological defects is important. Many centers across developing nations still follow a Neubauer's chamber/wet mount-based analysis of "pus cells."

This work was done with the following objectives: (1) to examine the incidence of leukocytospermia at a leading academic center examining a large number of infertility patients; (2) to ascertain the role of performing cytomorphological analysis in the work up of male infertility, with special reference to leukocytospermia and ascertaining any additional utility, and (3) to examine the cytomorphological features of sperms in cases of leucocytospermia.

\section{Materials and Methods}

The current work was a retrospective study conducted over a period of 3 months (November 2017 to January 2018) at the Clinical Pathology laboratory of our institute. Case data of couples being worked up for primary infertility referred to our laboratory for semen analysis was retrieved. All cases signed out as "leukocytospermia" in the study period were included for analysis. This included cases in which the Neubauer's chamber estimation of pus cells was more than $10^{6} / \mathrm{mL}$ and which was corroborated on smear examination. Cases in which a minimum of one pus cell per five oil immersion fields but not fitting the WHO definition of leukocytospermia were also included in the analysis .Cases in which pus cells were observed but in which the possibility of contamination could not be ruled out (increased squamous epithelial cells/presence of coccobacilli) were excluded from the study. Cases in which a rare or occasional pus cell was observed in the entire smear with a normal Neubauer's chamber count were excluded from the analysis.

As per our laboratory protocol, semen analysis was performed within 1 hour after ejaculation and evaluated as per the latest WHO guidelines for semen examination. ${ }^{1}$ It was ensured that all samples were collected after a minimum of 3 days of abstinence. Wet preparations were made for analysis of sperm count, motility, and other discernible cells, if any. Leukocytes, if noted were reported per high power field (hpf). The modified Neubauer's chamber was used to validate sperm counts and to provide leukocyte counts. Myeloperoxidase stain was done to confirm the white blood cells (WBC) counts. Sperm motility was graded as progressive motility, nonprogressive motility, and immobility. Viability of sperms was assessed on a $0.5 \%(\mathrm{w} / \mathrm{v})$ Eosin Y-stained preparation. Samples were also run on an automated sperm quality analyzer SQA-IIC-P (Medical Electronic Systems, Caesarea, Israel) for obtaining functional and motile sperm concentrations (MSCs). Papanicolaou (PAP)-stained smears were prepared for morphological analysis and sperms were subsequently scored for head, midpiece, and tail defects by observation in oil immersion at 1000x. As a single sperm may show multiple defects, overlap in classifying sperms within these categories was noted. Based on the morphological findings, the sperm deformity index (SDI) was calculated by dividing the total number of sperm defects by the total number of sperms evaluated through a random selection. In addition, the teratozoospermia index (TZI) was calculated by dividing the total number of sperm defects by the total number of abnormal sperms. Pus cell evaluation was also done on the cytosmear preparations with the number of pus cells documented per five hpf.

All procedures followed were in accordance with the ethical standards of the responsible committee on human experimentation (institutional and national) and with the Helsinki Declaration of 1975, as revised in 2008.

\section{Results}

Out of a total of 348 samples received during this period, 6 samples $(1.72 \%)$ were diagnosed as having "leukocytospermia." The couples evaluated in this work presented to the gynecology outpatient clinic of our institute with the complaint of an inability to conceive for an average (median) period of 1.5 years. The median age of the male subjects under evaluation was 32.0 years. The respective female partners had no previous conceptions and, on extensive evaluation for hormonal/structural dysfunction as a possible cause for infertility, had unremarkable test results. Five cases, in addition, were analyzed which, though failing to reach the WHO cut off for leukocytospermia, displayed the presence of pus cells ( $\geq 1 / 5 \mathrm{hpf}$ ) on cytosmear preparations ( $1.43 \%)$. One case in this subset also had post-treatment semen analysis. The results of the semen evaluation of all samples are summarized in - Table 1. Six out of the total cases evaluated $(6 / 11=54.5 \%)$ were those in which the Neubauer's chamber WBC count was more than the WHO defined cut off of leukocytospermia $\left(1 \times 10^{6} / \mathrm{mL}\right)$. All cases of leukocytospermia had pus cells on cytosmear evaluation also, albeit to varying degrees as illustrated in - Table 1. Out of the five additional cases examined, four had available automated counts. Three $(3 / 5=60 \%)$ cases in this subset showed oligospermia. Overall, six cases (54.5\%) showed oligospermia, four of which in addition had a low Neubauer's chamber white blood cell count $\left(<1 \times 10^{6} / \mathrm{mL}\right)$. Decreased motility and viability was noted in $70 \%$ of analyzed cases. Nine cases (81.8\%) showed reduced MSC, functional sperm concentration (FSC), and sperm motility index. Automated analyzer generated values showed more than $4 \%$ morphologically normal spermatozoa in all cases. However, analysis of the PAP-stained smears showed mid-piece defects in two cases (18.1\%) in the form of asymmetrical insertion of the midpiece into the head, thick or irregular neck ( - Fig. 1b), sharply bent neck ( $\boldsymbol{- \text { Fig. }}$ 2b) abnormally thin, or a combination of these. All cases diagnosed with leukocytospermia had an SDI and TZI which were in normal range $(\leq 1.6)$.

In the two cases in which pre and post treatment samples were evaluated, the first case showed a mild improvement in semen parameters whereas in the other, the derangements in counts and morphology persisted. Follow-up data of other cases was unavailable. 


\begin{tabular}{|c|c|c|c|c|c|c|c|c|c|c|c|c|c|c|c|}
\hline $\bar{n}$ & & & & : & $\stackrel{g}{0}$ & $\stackrel{6}{7}$ & 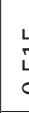 & & $\stackrel{g}{g}$ & $\stackrel{\llcorner}{\stackrel{0}{0}}$ & ก̊ & \multirow{7}{*}{ 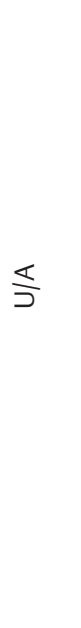 } & $\stackrel{\Re}{\check{r}}$ & $\stackrel{8}{8}$ & $\begin{array}{l}\stackrel{1}{n} \\
\stackrel{2}{\ominus}\end{array}$ \\
\hline $\bar{N}$ & & \llcorner & & $\stackrel{2}{?}$ & $\stackrel{\stackrel{\infty}{N}}{\underset{\sim}{n}}$ & $\stackrel{\mathscr{n}}{\tilde{c}}$ & 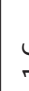 & & $\stackrel{\stackrel{n}{N}}{\longrightarrow}$ & - & - & & $\stackrel{\infty}{m}$ & $\stackrel{n}{\stackrel{n}{0}}$ & 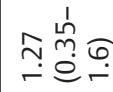 \\
\hline \multirow{5}{*}{ 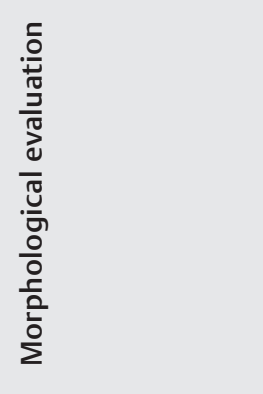 } & zo & 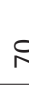 & & e & $\stackrel{0}{\curvearrowright}$ & 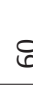 & & & $\stackrel{\infty}{\wedge}$ & ำ & டำ & & $\infty$ & $\stackrel{尺}{\simeq}$ & \\
\hline & $z$ & ભ̣ & & U & $\stackrel{\mathbb{I}}{I}$ & গ & & & $\cong$ & $\stackrel{\circ}{\circ}$ & 오 & & $\underset{t}{\nabla}$ & ঃ & \\
\hline & $\vdash$ & 7 & & -1 & - & $a$ & & & $\sim$ & 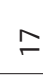 & $\stackrel{\circ}{-}$ & & $\stackrel{\sim}{\sim}$ & $\stackrel{\infty}{\sim}$ & \\
\hline & $\Sigma$ & 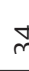 & & ת) & $\stackrel{\nu}{N}$ & $\varphi$ & & & ธn & เn & 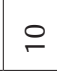 & & q & 우 & \\
\hline & $I$ & c & & 足 & $\pi$ & is & & & ๒ & $\stackrel{\infty}{\sim}$ & m & & in & $\stackrel{i}{\sim}$ & \\
\hline 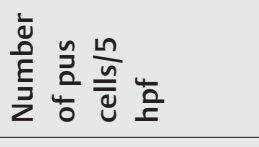 & & 6 & & ก & - & $\infty$ & & & $m$ & - & $N$ & $N$ & $\sim$ & $\nabla$ & \\
\hline 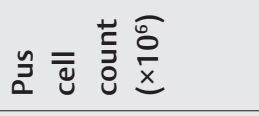 & & $\stackrel{5}{7}$ & & $\begin{array}{c}v \\
v\end{array}$ & 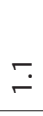 & $\stackrel{\llcorner}{\sim}$ & & & $\stackrel{\varphi}{+}$ & m. & $\stackrel{\infty}{0}$ & 。. & $\stackrel{\infty}{0}$ & $\stackrel{\nabla}{0}$ & 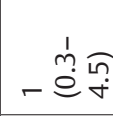 \\
\hline 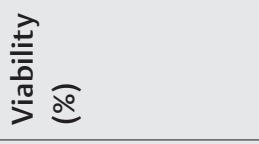 & & $\stackrel{\llcorner}{n}$ & & b & రే & 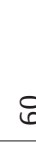 & & & $\stackrel{\llcorner}{m}$ & $\stackrel{\sim}{\sim}$ & $\stackrel{\llcorner}{\leftarrow}$ & $\stackrel{\frac{1}{J}}{J}$ & 으 & กี & 엔 \\
\hline$\sum_{n}$ & \multirow{6}{*}{ 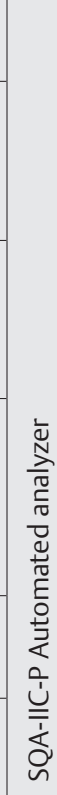 } & ケ & & va & 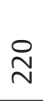 & ำ & 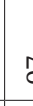 & & in & $\forall$ & ๒ & ó & $\stackrel{F}{F}$ & ஓ & 옹워 \\
\hline U⿳亠口冋亍 & & 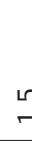 & & $\begin{array}{l}0 \\
\dot{j} \\
\end{array}$ & $\stackrel{\leftrightarrow}{\dot{q}}$ & $\stackrel{n}{n}$ & & & $\stackrel{\bullet}{\sim}$ & $N$ & $N$ & ¿̊. & $\stackrel{\overbrace{}}{=}$ & $\stackrel{\llcorner}{\stackrel{n}{=}}$ & 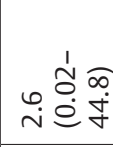 \\
\hline 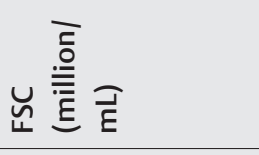 & & - & & ?. & $\stackrel{\llcorner}{\sim}$ & 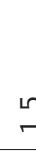 & & & $\stackrel{\bullet}{\leftarrow}$ & $\stackrel{\sim}{\sim}$ & $\stackrel{\sim}{\longrightarrow}$ & ర̋ & $\check{F}$ & $\stackrel{\leftrightarrow}{m}$ & 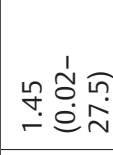 \\
\hline $\begin{array}{l}\text { वे } \\
\text { 응 } \\
\text { 는 } \\
\text { ¿े }\end{array}$ & & 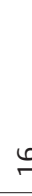 & & $n$ & $\stackrel{m}{m}$ & เั7 & & & $\approx$ & $\stackrel{\circ}{\circ}$ & 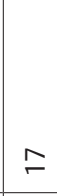 & $\stackrel{\frac{5}{J}}{3}$ & $\stackrel{6}{\circ}$ & $\bar{\sim}$ & 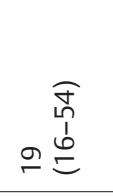 \\
\hline$\stackrel{\Sigma}{\mathrm{o}}$ & & $\stackrel{\llcorner}{\sim}$ & & f & กิ & $\nexists$ & & & $\stackrel{๑}{\ulcorner}$ & 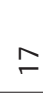 & $\stackrel{2}{2}$ & $\stackrel{\frac{1}{3}}{\partial}$ & $\stackrel{0}{\circ}$ & $\stackrel{\llcorner}{m}$ & 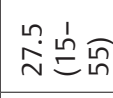 \\
\hline 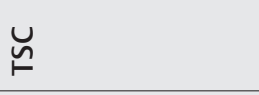 & & $\stackrel{\odot}{\circ}$ & & n. & $\infty$ & 5 & n & & $\doteq$ & $\stackrel{\sim}{\sim}$ & 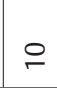 & $\frac{\leqslant}{J}$ & $\mp$ & $m$ & $\stackrel{n}{\tilde{N}} \stackrel{1}{=} \widetilde{\infty}$ \\
\hline 离 & & $\hat{\sim}$ & & y & $\stackrel{\infty}{\sim}$ & $\tilde{m}$ & 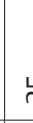 & & $\stackrel{\llcorner}{m}$ & i & $\stackrel{2}{N}$ & $\tilde{m}$ & $\stackrel{\sim}{m}$ & $\stackrel{\infty}{\sim}$ & 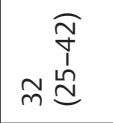 \\
\hline 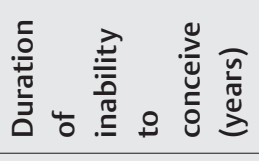 & & 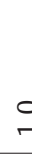 & & ? & 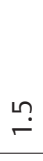 & $\stackrel{c}{c}$ & & & $\stackrel{\circ}{i}$ & $\stackrel{\circ}{-}$ & $\stackrel{\circ}{-}$ & 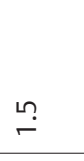 & 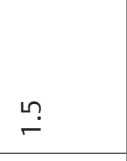 & $\stackrel{\circ}{-}$ & 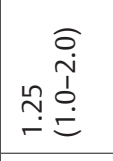 \\
\hline 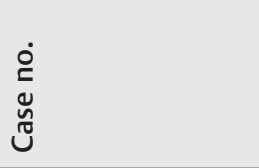 & & $r$ & & v & $m$ & $\nabla$ & & & 0 & $r$ & $\infty$ & 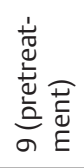 & 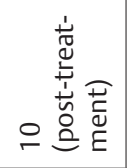 & $\mp$ & 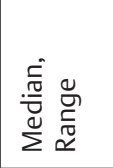 \\
\hline
\end{tabular}




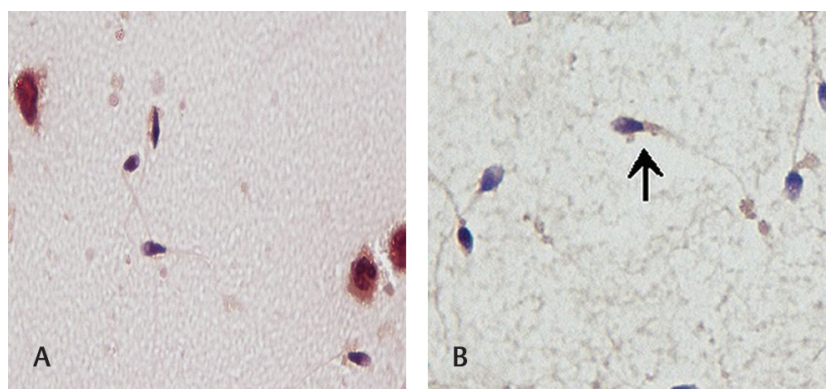

Fig. 1 Papanicolaou-stained semen cytosmears show (A) tapered heads, bent neck pieces, and polymorphonuclear cells (Papanicolaou stain, 100×); (B) Mid piece defect-thick midpiece inserting into the sperm head, inset shows a higher magnification highlighting the defective sperm neck (Papanicolaou stain, 100× and 1000×).
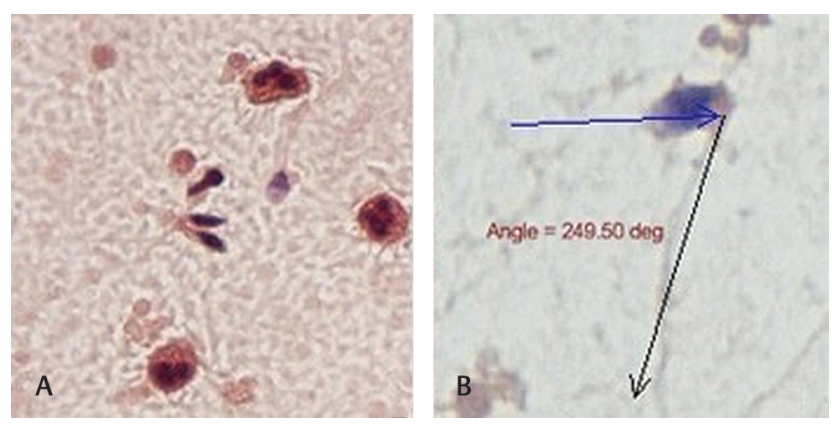

Fig. 2 Semen smears show (A) tapered spermatozoa heads in a background of polymorphonuclear cells; (B) Bent neck piece displaying an angle of 249.5 degrees (Papanicolaou stain, 200× and 1000×).

\section{Discussion}

Leucocytospermia is commonly associated with infection or inflammation of male accessory glands and urogenital tract. ${ }^{2}$ There is a wide variation of the prevalence of leucocytospermia, ranging from 16.1 to $60.7 \% .^{10}$ Increased leucocytes lead to increased ROS and sperm dysfunction by lipid peroxidation (-Fig. 3). There are various causes of leucocytospermia which may be classified as infectious and noninfectious. Infectious causes include bacterial and viral infections of the genitourinary tract, commonly prostatitis and epididymitis. Commonly implicated organisms include Chlamydia trachomatis, Ureaplasma urealyticum, and Escherichia coli. Viruses such as herpes simplex, cytomegalovirus, hepatitis B may also be causative. Noninfectious causes include consumption of nicotine, marijuana, and alcohol. ${ }^{11}$ Other factors such as prolonged abstinence and anal intercourse may also lead to an increased number of white blood cells in the semen. ${ }^{12}$ Lipid peroxidation impacts the polyunsaturated fatty acids in sperm cell membranes which lead to DNA damage. This coupled with impaired repair mechanisms and maturation lead to decreased sperm motility, abnormal morphology, and overall decrease in sperm fertilization capacity and viability which explains the possible cause of infertility in our cases, in addition to oligospermia seen in around half of our cases. ${ }^{13}$

The present work emphasizes the role of a detailed morphological analysis of semen in the clinical pathology laboratory. With the advent of automated semen analysis, parameters such as total FSC, MSC, sperm motility index, percentage of progressively motile spermatozoa, and percentage of morphologically normal spermatozoa are readily available. In our study, however, despite more than $4 \%$ morphologically normal sperms in all our cases, two cases (18.1\%) showed midpiece defects on cytological evaluation, an observation also highlighted in patients with leucocytospermia by Thomas et al in 1997. ${ }^{14}$ This work described 79 cases of semen analyses finding a positive correlation between polymorphonuclear cells and midpiece abnormalities and a negative correlation with normal sperms. Both these cases had an increased number of pus cells both on Neubauer's chamber as well as on PAP-stained smears.

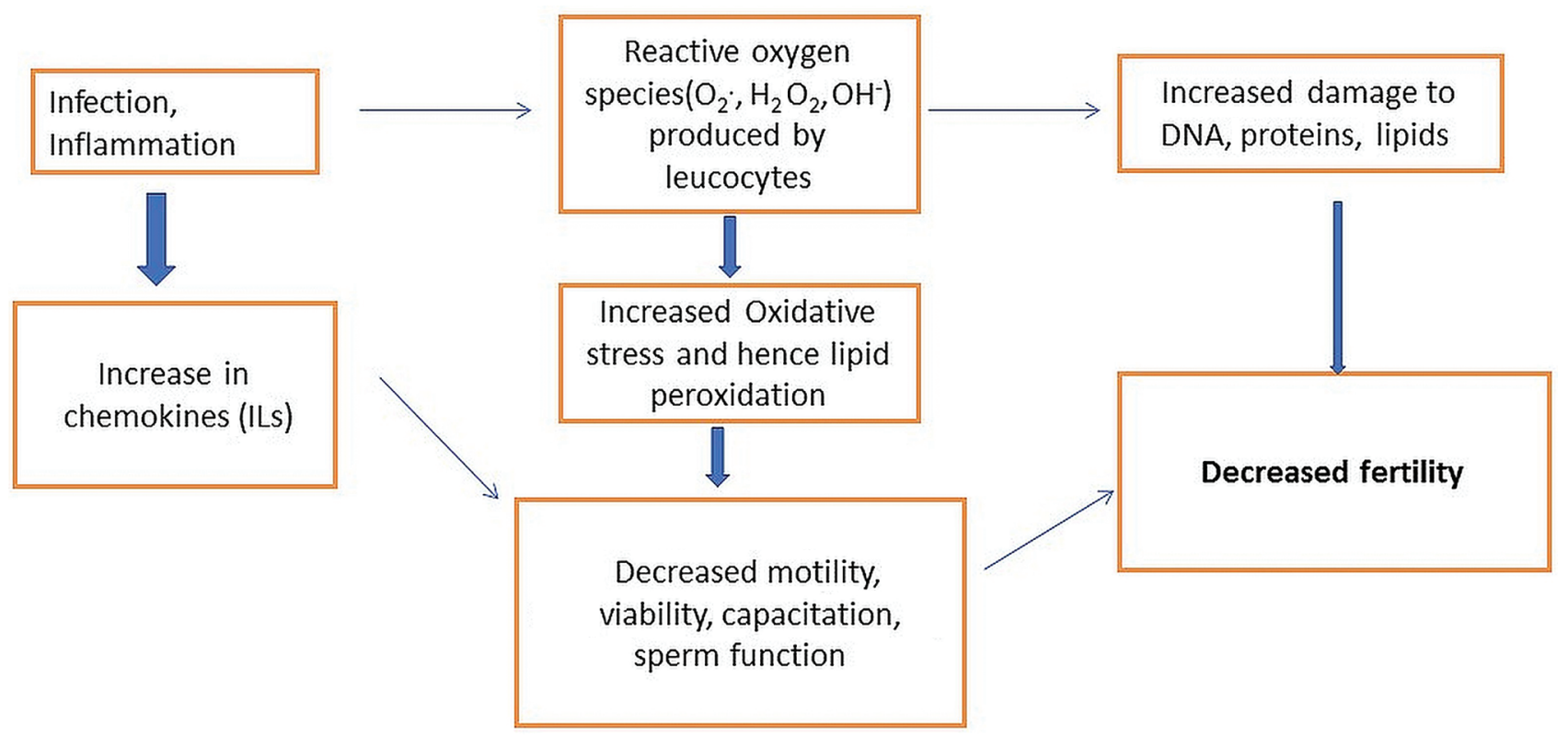

Fig. 3 Schematic diagram illustrating the role of leukocytospermia in male infertility. 
All our cases (6/11) displaying more than $1 \times 10^{6} / \mathrm{mL}$ pus cells, i.e., leukocytospermia, displayed pus cells on cytosmear evaluation. In addition, five (45.4\%) cases showed pus cells (one and more) on evaluation of five hpfs. These all showed pus cell counts less than $1 \times 10^{6} / \mathrm{mL}$ on modified Neubauer chamber estimation. This could possibly be explained by the pus cells inducing an altered microenvironment for the spermatozoa leading to nonspecific microaggregates, as described by Bhardwaj et al. ${ }^{15}$ These being heavier tend to settle downward and despite adequate mixing of the semen, may escape being sampled into the Neubauer's chamber resulting in false low counts. Previous work by Moretti et al has also suggested a hampered semen interpretation in the presence of pus cells. ${ }^{16}$ However, the authors concluded that pus cells may have no pathogenic role which is contrary to our work, wherein all cases having autoanalyzer and smear documentation of pus cells presented with infertility. Our findings hence may suggest a greater need to validate automated values with cytological evaluation as part of standard practice.

Our cases showed a normal SDI in both the patients which was in contrast to findings by Aziz et al who reported a positive correlation between leucocytospermia and higher mean SDI score which was 1.9 in their study.$^{17}$ This may be due to the fact that leukocytes scavenge damaged sperms resulting in a possibly normal SDI. All the remaining cases also showed normal SDI and TZI scores. Menkveld and Kruger observed many tapered heads in cases of leucocytospermia as seen in our cases in addition to other features of poor sperm morphology..$^{18}$ Tapered heads were also seen in the cases which had mid piece defects.

All cases described herein highlight a significant correlation between leucocytospermia and semen parameters like SMI, MSC, FSC, motility, and viability suggesting an association with poor sperm quality. The morphologist's report assumes critical importance, as a recent review of management of leucocytospermia has suggested, antibiotics and antioxidants may improve sperm quality and subsequent chances of fertility. ${ }^{2}$

The current work is limited by the absence of immunocytological evaluation of the white blood cells on the samples and microbiological correlation including reflexive semen culture. to document any association with bacteriospermia in our cases. As the compliance of subjects to give a second sample for culture in our sociocultural setting is low, this was not performed on our study cohort. In addition, adequate follow-up clinical data was not available despite the best of our efforts. Further prospective studies on larger cohorts with multidisciplinary correlation, are required to validate a practical and user-friendly morphological criteria of diagnosing leukocytospermia in challenging conditions, as well as the actual clinical import of this observation in indigenous study populations.

To conclude, leukocytospermia is a diagnostic and clinical enigma. Challenges remain in the diagnosis in a routine laboratory setting with resource constraints being a real issue. In this scenario, a thorough cytomorphological analysis on simple and inexpensive PAP-stained preparations of semen smears can possibly improve the detection of leukocytospermia as well as morphological indicators of sperm quality, even in settings where automated semen analyzers may not be available. It could double up as a useful tool not only in arriving at the correct diagnosis in cases of male infertility but also as a quality control measure to screen out cases where the sample may appear contaminated or unsatisfactory for analysis. As seen herein, it may also aid to negate the vagaries seen in Neubauer chamber analysis of cell counts, still being practiced in many laboratories.

\section{Authors' Contributions}

V.P. contributed toward the collection and analysis of data, providing intellectual content of critical importance, editing, and final approval of the manuscript. K.G. contributed toward collection and analysis of data, literature review, drafting, and final approval of the manuscript. S.H. contributed toward the acquisition of data, providing intellectual content of critical importance, editing, and final approval of the manuscript. S.S. contributed toward the concept of work, pathology inputs, providing intellectual content of critical importance, editing, and final approval of the manuscript. Su.S. contributed toward the concept of work, pathology inputs, providing intellectual content of critical importance, editing, and final approval of the manuscript.

\section{Ethical Approval}

The current work has been approved by the Institutional Ethics Committee. This article does not contain any studies with animals or human subjects performed by any of the authors.

\section{Financial Disclosure}

None of the authors have any financial disclosures to make. There are no commercial interests of any of the authors involved. Honorariums, grants, or other forms of payment have not been received by any of the authors to produce the manuscript.

\section{Conflict of Interest}

There is no conflict of interest to be declared.

\section{References}

1 World Health Organization (WHO), WHO Laboratory Manual for the Examination and Processing of Human Semen. 5th ed. Geneva: WHO; 2010

2 Jung JH, Kim MH, Kim J, et al. Treatment of leukocytospermia in male infertility: a systematic review. World J Mens Health 2016;34(3):165-172

3 Kaleli S, Oçer F, Irez T, Budak E, Aksu MF. Does leukocytospermia associate with poor semen parameters and sperm functions in male infertility? The role of different seminal leukocyte concentrations. Eur J Obstet Gynecol Reprod Biol 2000;89(2):185-191

4 Kiessling AA, Lamparelli N, Yin HZ, Seibel MM, Eyre RC. Semen leukocytes: friends or foes? Fertil Steril 1995;64(1):196-198

5 Ford WC. Regulation of sperm function by reactive oxygen species. Hum Reprod Update 2004;10(5):387-399

6 Domes T, Lo KC, Grober ED, Mullen JB, Mazzulli T, Jarvi K. The incidence and effect of bacteriospermia and 
elevated seminal leukocytes on semen parameters. Fertil Steril 2012;97(5):1050-1055

7 Henkel R, Kierspel E, Stalf T, et al. Effect of reactive oxygen species produced by spermatozoa and leukocytes on sperm functions in non-leukocytospermic patients. Fertil Steril 2005;83(3):635-642

8 Sharma RK, Pasqualotto AE, Nelson DR. Thomas AJ Jr, Agarwal A. Relationship between seminal white blood cell counts and oxidative stress in men treated at an infertility clinic. J Androl 2001;22(4):575-583

9 Sadri Ardekani H, Akhondi MM. Identification and treatment of leucocytospermia in infertile men. J Reprod Infertil 2007;7:401-410

10 Lackner JE, Lakovic E, Waldhör T, Schatzl G, Marberger M. Spontaneous variation of leukocytospermia in asymptomatic infertile males. Fertil Steril 2008;90(5):1757-1760

11 Wolff $\mathrm{H}$. The biologic significance of white blood cells in semen. Fertil Steril 1995;63(6):1143-1157

12 Sadri-Ardekani H, Akhondi MM. Identification and treatment of leukocytospermia in infertile men. J Reprod Infertil 2007; 7:401-410
13 Sharma RK, Agarwal A. Role of reactive oxygen species in male infertility. Urology 1996;48(6):835-850

14 Thomas J, Fishel SB, Hall JA, Green S, Newton TA, Thornton SJ. Increased polymorphonuclear granulocytes in seminal plasma in relation to sperm morphology. Hum Reprod 1997;12(11):2418-2421

15 Bhardwaj P, Rana K, Vander H, Bhandari P, Prabha V. Sperm-impairing Escherichia coli, alcohol and male infertility: an in vivo study. J Med Microb Diagn 2015;4:1. DOI: 10.4172/21610703.1000195

16 Moretti E, Capitani S, Figura N, et al. The presence of bacteria species in semen and sperm quality. J Assist Reprod Genet 2009;26(1):47-56

17 Aziz N, Agarwal A, Lewis-Jones I. Sharma RK, Thomas AJJr. Novel associations between specific sperm morphological defects and leukocytospermia. Fertil Steril 2004;82(3):621-627

18 Menkveld R, Kruger TF. Sperm morphology and male urogenital infections. Andrologia 1998;30(suppl 1):49-53 